\title{
Microbiota Oral e Sua Implicação no Binômio Saúde-Doença
}

\author{
José Carlos Costa dos Santos Júnior ${ }^{1}$, Tasciano dos Santos Santa Izabel ${ }^{2}$
}

\begin{abstract}
RESUMO
A cavidade oral apresenta uma grande diversidade de microrganismos. A microbiota oral encontra-se normalmente em harmonia com o hospedeiro, porém em condições anormais tem o potencial de gerar infecções bucais e sistêmicas graves. 0 presente estudo teve como objetivo verificar a importância da microbiota oral no processo saúde-doença. Foi realizada uma revisão de literatura, por meio de pesquisa nas bases de dados: Lilacs, BBO, Scientific Electronic Library On-line (SciELO) e Biblioteca Virtual em Saúde (BVS), tendo como critérios de inclusão: artigos científicos que tratassem sobre a temática, publicados entre 2000 e 2018 em português, inglês e espanhol. Os resultados demonstraram que a microbiota oral sofre influência da temperatura, $\mathrm{pH}$, presença de oxigênio, disponibilidade de nutrientes e os mecanismos de defesa do hospedeiro. Ao ocorrer desregulações desses parâmetros a microbiota é alterada, o que desencadeia a colonização por patógenos. As infecções sistêmicas (cardiopatias e infecções respiratórias) correlacionadas apresentam relações diretas e bidirecionais, em que o desfecho quase sempre é o óbito. Observa-se, entretanto, a necessidade de pesquisas mais detalhadas para esclarecer esta real influência.
\end{abstract}

Palavras-chave: Odontologia. Microbiologia. Microbiota. Saúde bucal. Infecção focal.

\section{ORAL MICROBIOTA AND ITS IMPLICATION IN BINOMIO HEALTH-DISEASE}

\begin{abstract}
The oral cavity presents a great diversity of microorganisms. The oral microbiota is normally in harmony with the host, but in abnormal conditions it has the potential to generate serious oral and systemic infections. The present study aimed to verify the importance of oral microbiota in the health-disease process. A review of the literature was carried out by searching the databases: Lilacs, BBO, Scientific Electronic Library Online (Scielo) and Virtual Health Library (VHL). The criteria for inclusion were: scientific articles dealing with the subject, published between 2000 and 2018 in Portuguese, English and Spanish. The results showed that the oral microbiota is influenced by temperature, $\mathrm{pH}$, presence of oxygen, availability of nutrients and defense mechanisms of the host. When deregulations of these parameters occur the microbiota is altered, which triggers colonization by pathogens. Correlated systemic infections (cardiopathies and respiratory infections) present direct and bidirectional relationships, where the outcome is almost always death. However, there is a need for more detailed research to clarify this real influence.
\end{abstract}

Keywords: Dentristry. Microbiology. Microbiota. Oral health. Focal infection.

Recebido em: 6/1/2019

Alterações requeridas em: 3/4/2019

Aceito em: 8/5/2019

\footnotetext{
${ }^{1}$ Graduando de Odontologia pela Unidade de Ensino Superior de Feira de Santana (Unef). jozesant82@gmail.com

2 Doutor em Botânica (Uefs), docente da Unidade de Ensino Superior de Feira de Santana (Unef). tazuefsbot@gmail.com
} 


\section{INTRODUÇÃO}

A cavidade bucal apresenta condições físico-químicas características que propiciam a colonização e o crescimento de um amplo número de microrganismos (KIM et al., 2018). Estes são importantes na manutenção do estado de saúde do organismo humano, como é o caso de algumas cepas de Lactobacillus, um importante probiótico (TERAl et al., 2015).

Em condições saudáveis, a microbiota oral relaciona-se harmonicamente com o hospedeiro, similarmente ao que ocorre com os outros micro-habitats do corpo humano (MOOM; LEE, 2016). A microbiota da cavidade bucal começa a ser estabelecida logo após o nascimento e sofre alterações na quantidade e diversidade de microrganismos ao longo da vida, quando se nota a influência epigenética sobre esse ambiente (MORENO et al., 2017). Entre os fatores que auxiliam na relação entre ela e o organismo destacam-se a temperatura, $\mathrm{pH}$, presença de oxigênio (potencial oxidação-redução), nutrientes (endógenos e exógenos) e a defesa do organismo (COSTALONGA; HERZBERG, 2014; NASRY et al., 2016). Todos esses fatores são importantes no binômio saúde-doença, pois modulam a colonização por determinados microrganismos, os quais serão capazes de sobreviver e se proliferar no ambiente e, assim, estabelecer a microbiota residente (TERAl et al., 2015; KIM et al., 2018).

A quebra desta harmonia, por alguma alteração no ambiente bucal, favorece a proliferação de espécies patogênicas e, assim, o desenvolvimento de doenças, uma relação de disbiose, em que, a depender do grau de comprometimento, pode afetar outros sistemas além do sistema estomatognático (MORAIS et al., 2006).

As bactérias e seus produtos desempenham um papel fundamental na indução e, principalmente, na perpetuação das alterações patológicas que acometem os tecidos duros e moles da cavidade bucal, esta em maior extensão, pois tal correlação já está corroborada pela literatura (ZANDONÁ; SOUZA, 2017).

Segundo Almeida et al. (2006), as desordens bucais alteram a modulação da microbiota oral, especialmente a doença periodontal, podendo atuar como foco de disseminação de microrganismos patógenos, com efeito metastático sistêmico, especialmente em pessoas imunocomprometidas ou com comorbidades.

O presente estudo teve como objetivo demonstrar que a microbiota oral tem capacidade de influenciar o processo saúde-doença, tanto no sistema estomatognático quanto nos outros sistemas que compõem o complexo organismo humano.

\section{METODOLOGIA}

A presente pesquisa trata-se de uma revisão de literatura realizada através de bancos de dados em saúde nacionais e internacionais: Lilacs, BBO, Scientific Electronic Library On-line (SciELO) e Biblioteca Virtual de Saúde (BVS).

Nesse levantamento, foram selecionadas as palavras-chave, seguindo os Descritores em Ciências da Saúde (Desc.). Os termos na língua portuguesa, Odontologia, Microbiologia, Microbiota, Saúde bucal e Infecção focal, foram inseridos nas bases de buscas e separados no formulário avançado pelos operadores booleanos "AND" e "OR".

Foram selecionados apenas artigos científicos com o texto completo disponível nas línguas portuguesa, inglesa e espanhola, publicados entre 2000 e 2018. Não foram contemplados na presente pesquisa estudos de conclusão de curso: monografias, dissertações e/ou teses; estudos de caso e controle e relatos de casos.A seleção inicial aconteceu detectando os descritores na leitura do título do estudo e posteriormente selecionando-os por meio da técnica sugerida pelo método Prisma, que consiste na leitura do resumo, logo após o artigo selecionado foi lido por completo, decidindo-se então pela sua inclusão ou exclusão, ao ponderar seu referencial teórico, critérios de elegibilidade e implicações dos principais achados (GALVÃO; PANSANI, 2015). Depois de estabelecidos todos os critérios da metodologia foram contemplados para a pesquisa 25 estudos representados no fluxograma da Figura 1.

Figura1 - Fluxograma dos estudos contemplados na amostra da pesquisa

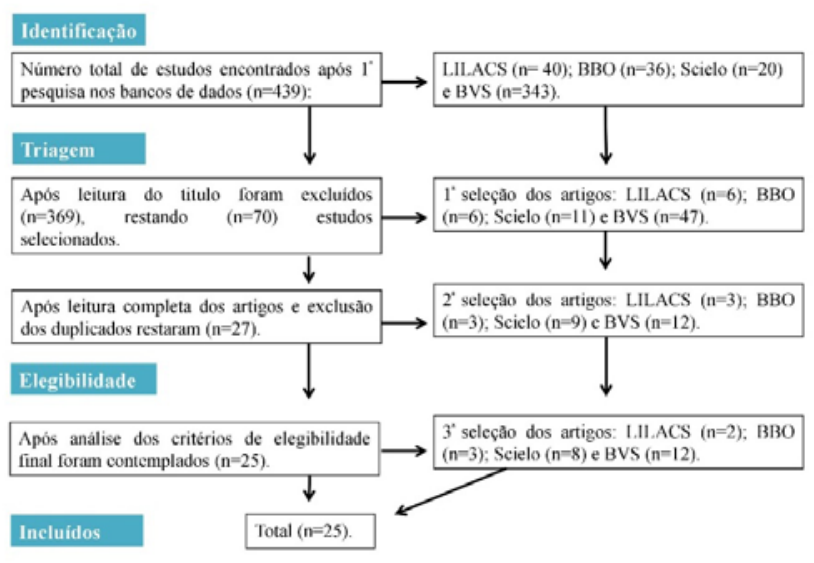

Fonte: Dados da pesquisa. 


\section{RESULTADOS}

Todas as superfícies do corpo humano são continuamente expostas à colonização por uma vasta diversidade de microrganismos que geralmente vivem em harmonia com o hospedeiro (MORAIS et al., 2006; MORENO et al., 2017).

A composição da microbiota oral é distinta das outras partes do corpo humano, pois suas características específicas geram um favorecimento da colonização por determinadas espécies, consequentemente constituindo microbiotas singulares. Tal distinção de micro-habitats ocorre até mesmo dentro da própria cavidade bucal (COSTALONGA; HERZBERG, 2014; NASRY et al., 2016).

Nem todos os microrganismos que entram na boca conseguem colonizar este ambiente e se manter nele. Mesmo dentro dessa cavidade existem diferentes locais que favorecem a colonização por distintos microrganismos (MORENO et al., 2017). Ou seja, nem todos os microrganismos ao qual esta superfície é exposta diariamente são capazes de compor a microbiota residente.

Com isso, a cavidade oral em indivíduos saudáveis tem uma microbiota bem equilibrada que consiste em mais de 700 espécies, conforme determinado pelo Human Oral Microbiome Database (HOMD, 2018). Tal confirmação de tamanha pluralidade desta microbiota foi permitida por uma análise clonal do gene RNAr 16S, quando se revelou que, além de algumas espécies de fungos e vírus, diversas bactérias, incluindo Streptococcus mutans e membros dos gêneros Actinomyces, Bifidobacterium, Lactobacillus, Propionibacterium e Veillonella estão presentes neste micro-habitat (TERAl et al., 2015; KIM et al., 2018).

$\mathrm{Na}$ boca existem dois tipos de superfícies passíveis de colonização: as superfícies descamativas e a dos tecidos duros. Nas superfícies descamativas, como as mucosas, ocorre o processo fisiológico de descamação celular contínua, o que impede o acúmulo e a organização de microrganismos em biofilmes (COSTALONGA; HERZBERG, 2014). Já as superfícies dos tecidos duros, isto é, os dentes e as superfícies retentivas, como próteses, aparelhos, cálculos dentários e restaurações, há o favorecimento da colonização microbiana por não ocorrer descamação (MORAIS et al., 2006; KIM et al., 2018).

Nesse aspecto biológico vale ressaltar ainda a importância da saliva e do fluido do sulco gengival (FSG), pois ambos influenciam a colonização de diferentes nichos na cavidade bucal, servindo de nutrientes endógenos para os microrganismos e modulando seu crescimento (TERAl et al., 2015; NASRY et al., 2016).
Desse modo, a presença de dentes, mucosas, FSG e saliva diferencia o ambiente bucal de outros locais do corpo humano (GEORGE et al., 2016; TERAl et al., 2015).

A microbiota oral sofre influência tanto de fatores externos (tabagismo, alcoolismo, antibioticoterapia, permanência em ambientes hospitalares, estado nutricional e higiene bucal) quanto intrínsecos ao paciente, como a idade e o estado imunológico (ALMEIDA et al., 2006; MORAIS et al., 2006).

Segundo Morais et al. (2006), uma perturbação deste equilíbrio propicia o aumento de microrganismos patógenos (como a proliferação de cepas de Actinobacillus actinomycetemcomitans, Porphyromonas gingivalis ou Tannerella forsythensis) e um decréscimo dos microrganismos simbiontes, provocando desordens orais, como a doença periodontal ou a cárie dentária, observando-se que dependendo da extensão desta desordem poderá afetar, de forma uni ou bidirecional, outros sistemas do corpo humano.

Apresenta-se a seguir, na Tabela 1, os resultados encontrados nos estudos inclusos nesta revisão para estabelecer o consenso existente na literatura sobre a influência da microbiota oral no binômio saúde-doença.

\section{DISCUSSÃO}

As condições físico-químicas da microbiota oral que propiciam a colonização e o crescimento de um amplo número de microrganismos são moduladas por fatores específicos, que possuem relação com determinantes socioeconômicos, culturais e biológicos aos quais o hospedeiro está submetido (ALMEIDA et al., 2006). Entre os fatores que favorecem a colonização por diferentes espécies em distintos nichos destacam-se a temperatura, o $\mathrm{pH}$, a presença de oxigênio, disponibilidade de nutrientes e os mecanismos de defesa do hospedeiro (COSTALONGA; HERZBERG, 2014; NASRY et al., 2016). Os fatores que influenciam na modulação da microbiota oral em quadros de simbiose (saúde) e disbiose microbiana (doença) são discutidos na Tabela 2.

A temperatura adequada, por volta de $35-36^{\circ} \mathrm{C}$, propociona condições para o crescimento e metabolismo de espécies que compõem a microbiota normal (MOON; LEE, 2016). Alterações bruscas nesse parâmetro desencadeiam a proliferação microbiana ao modificar o pH, a atividade iônica, a agregação de biomoléculas e a solubilidade de gases, interferindo bidirecionalmente nos outros fatores (NASRY et al., 2016).

$\mathrm{O} \mathrm{pH}$ do meio propicia a seleção dos microrganismos aptos para colonizar a boca e se desenvolver. Muitas espécies requerem um $\mathrm{pH}$ próximo do neutro 
Tabela 1 - Resultados encontrados na literatura sobre a influência da microbiota oral no binômio saúde-doença

\begin{tabular}{|c|c|c|}
\hline AUTOR & ANO & RESULTADO \\
\hline $\begin{array}{c}\text { Ghannoum } \\
\text { et al. }\end{array}$ & 2010 & $\begin{array}{l}\text { A distribuição e o perfil de espécies de fungos na cavidade bucal de indivíduos saudá- } \\
\text { veis é complexa. A relevância clínica para a presença de uma população diversificada de } \\
\text { espécies de fungos na cavidade oral é desconhecida. É possível que a presença de um } \\
\text { determinado isolado fúngico (por exemplo, Candida, Aspergillus, Cryptococcus e Fusa- } \\
\text { rium) em um indivíduo pode ser o primeiro passo predispondo o hospedeiro a infecções } \\
\text { oportunistas. A respeito disso, colonização oral por Candida é conhecida como um fator } \\
\text { de risco para infecções como a candidíase em pacientes imunocomprometidos. }\end{array}$ \\
\hline $\begin{array}{c}\text { Gadelha e } \\
\text { Araújo }\end{array}$ & 2011 & $\begin{array}{l}\text { A má higienização bucal (redução do fluxo salivar, a diminuição do pH salivar, o decrés- } \\
\text { cimo do reflexo da tosse) dos pacientes internados associada à aspiração do conteúdo } \\
\text { presente na orofaringe e à imunidade comprometida provocam a contaminação das } \\
\text { vias respiratórias inferiores. Dessa forma, o biofilme dental age como potencial foco } \\
\text { infeccioso causador de pneumonia nosocomial. }\end{array}$ \\
\hline Terai et al. & 2015 & $\begin{array}{l}\text { Há evidências de que os probióticos orais apresentam benefícios para a saúde. As ce- } \\
\text { pas de Lactobacillus e Bifidobacterium isoladas de amostras orais humanas reduziram } \\
\text { o mau odor oral causado por compostos de enxofre volátil (VSCs) e preveniram a cárie, } \\
\text { doença periodontal e outras infeç̧ões, como a candidíase oral. }\end{array}$ \\
\hline Nasry et al. & 2016 & $\begin{array}{l}\text { Em condições de saúde bucal, os biofilmes estão em estado de homeostase microbiana, } \\
\text { com a grande maioria da microbiota sendo comensal ou mutualista. Em condições de } \\
\text { doença bucal, a composição, quantidade e estabilidade da microbiota bucal são altera- } \\
\text { das. Os fatores que influenciam a composição microbiana incluem genética, defesas do } \\
\text { hospedeiro, interações microbianas, receptores usados para fixação, acidogenicidade e } \\
\text { fluxo salivar. }\end{array}$ \\
\hline $\begin{array}{c}\text { Kawamoto } \\
\text { et al. }\end{array}$ & 2016 & $\begin{array}{l}\text { Aggregatibacter actinomycetemcomitans é considerado o membro mais prevalente do } \\
\text { Grupo Hacek, formado por bactérias anaeróbias facultativas Gram-negativas relaciona- } \\
\text { das à endocardite e periodontite agressiva. }\end{array}$ \\
\hline Kim et al. & 2018 & $\begin{array}{l}\text { Alterações na microbiota salivar podem se correlacionar com o desenvolvimento de } \\
\text { cárie dentária e mecanismos mediadores dessa associação precisam ser estudados em } \\
\text { maiores detalhes. }\end{array}$ \\
\hline
\end{tabular}

Fonte: Elaborada pelos autores.

para crescerem (o pH normal da cavidade bucal em sua maioria), sendo sensíveis a meios extremamente ácidos ou alcalinos (ZANDONÁ; SOUZA, 2017). Certos nichos específicos da cavidade bucal, como o biofilme dental, favorecem a proliferação de microrganismos acidogênicos (capazes de produzir ácidos) e acidúricos, capazes de sobreviver em meio ácido (MEDINA; VEIGA; ZULUAGA, 2014; ZANDONÁ; SOUZA, 2017). Já em sítios de inflamação gengival é favorecida a proliferação de microrganismos álcali-tolerantes, como é o caso dos periodontopatógenos (ALMEIDA et al., 2006).

O crescimento microbiano depende da disponibilidade de nutrientes, os quais podem ser endógenos, presentes na saliva e no FSG, ou exógenos, provenientes da dieta do hospedeiro (COSTALONGA; HERZBERG, 2014). Entre as fontes de nutrientes presentes na dieta, os carboidratos fermentáveis são os nutrientes exógenos que mais interferem na modu- lação de população da microbiota oral (GADELHA; ARAÚJO, 2011; NASRY et al., 2016). As bactérias, principalmente, utilizam esses carboidratos para obtenção de energia, produzindo ácidos como produto final do metabolismo, modificando o $\mathrm{pH}$ local (BARROSO; CORTELA: MOTA, 2014).

Outro fator que afeta este crescimento é a diferença na concentração de oxigênio nos diferentes locais que constituem a cavidade bucal. A maioria dos microrganismos presentes são anaeróbios facultativos ou anaeróbios restritos (BARROSO; CORTELA; MOTA, 2014; NASRY et al., 2016). Dessa forma, alguns locais em que a concentração de oxigênio é reduzida, como a parte interna dos biofilmes e a região de fundo de sulco, ocorre maior presença de anaeróbios restritos (COSTALONGA; HERZBERG, 2014). Além disso, os radicais livres formados a partir do oxigênio são extremamente deletérios aos microrganismos, em especial à célula bacteriana. Ou seja, nota-se que é o grau de oxidação-redução em 
um local que governa a sobrevivência e crescimento relativo desses microrganismos (ZANDONÁ; SOUZA, 2017; KIM et al., 2018).

Ainda no quesito modulação da microbiota oral, pode-se elencar os mecanismos de defesa do hospedeiro. Esta é estabelecida, além do sistema imunológico, pela barreira física das mucosas e por fatores de defesa específica e não específica (DARVEAU, 2010; NASRY et al., 2016). No componente de defesa do tipo não específica entra a ação de glicoproteínas (mucinas), de enzimas (lactoferrina e lisozima) e de peptídeos antimicrobianos presentes na saliva (COSTALONGA; HERZBERG, 2014). Essas biomoléculas auxiliam na aglutinação de microrganismos, facilitando sua deglutição juntamente com a saliva e na degradação de componentes vitais da célula bacteriana - efeito bactericida (COSTALONGA; HERZBERG, 2014; MORENO et al., 2017). Os componentes de defesa específica do organismo é composta pelos linfócitos, células de Langherans e imunoglobulinas, em especial as IgG e IgA (DARVEAU, 2010; MORENO et al., 2017).

\section{Microbiota Oral no Binômio Saúde-doença}

A microbiota oral é composta por uma variedade de microrganismos que desempenham papéis significativos no binômio saúde-doença. Tal como as bactérias que mantêm a saúde oral e sistêmica, mas em condições anormais também podem causar doenças, assim como os bacteriófagos moldam a diversidade deste micro-habitat, influenciando indiretamente no equilíbrio da sua homeostase microbiana (POZHITKOV et al., 2015).

Os fungos também desempenham um papel importante na regulação da microbiota oral. Ghannoum et al. (2010) estudaram os fungos da microbiota oral de 20 indivíduos saudáveis. Os gêneros mais abundantes registrados foram: Candida, Cladosporium, Aureobasidium, Aspergillus, Fusarium e Cryptococcus, entretanto a relevância clínica para a presença de uma população diversificada de espécies de fungos na cavidade oral é desconhecida. É possível que a presença de um determinado isolado fúngico pode predispor o hospedeiro a infecções oportunistas. A respeito disso, a colonização oral por Candida é conhecida como um fator de risco para infecções, como a candidíase, em pacientes imunocomprometidos (GHANNOUM et al., 2010).

A maioria das doenças bucais são patologias infecciosas causadas por microrganismos geralmente encontrados no biofilme dentário, representadas principalmente pela cárie e doença periodontal (DARVEAU, 2010; NASRY et al., 2016). As manifestações clínicas de infecções orais estão relacionadas à atividade desses microrganismos (síntese de ácidos, endotoxinas e antígenos) e as respostas imunes do hospedeiro direcionadas contra os mesmos (KIM et al., 2018).

A desregulação dos fatores que determinam o equilíbrio entre saúde bucal e doença provoca alteração da homeostase microbiana e, consequentemente, o surgimento de doenças orais (NASRY et

Tabela 2 - Fatores moduladores da microbiota oral e atuação no processo de saúde-doença

\begin{tabular}{|l|l|l|l|}
\hline $\begin{array}{l}\text { FATORES MODULA- } \\
\text { DORES }\end{array}$ & \multicolumn{1}{|c|}{ AÇÃO DURANTE A SIMBIOSE } & AÇÃO DURANTE A DISBIOSE & REFERÊNCIA \\
\hline TEMPERATURA & $\begin{array}{l}\text { Condições para crescimento e o me- } \\
\text { tabolismo de espécies simbiontes. }\end{array}$ & Proliferação de periodontopatógenos. & $\begin{array}{l}\text { (COSTALONGA; } \\
\text { HERZBERG, 2014). }\end{array}$ \\
\hline FATOR PH (SALIVA) & $\begin{array}{l}\text { Seleção dos microrganismos aptos } \\
\text { para colonização. }\end{array}$ & $\begin{array}{l}\text { Proliferação de microrganismos acido- } \\
\text { gênicos (favorece cárie dentária). Na in- } \\
\text { flamação gengival ocorre proliferação de } \\
\text { periodontopatógenos. }\end{array}$ & $\begin{array}{l}\text { (MULUANA; VEGA; } \\
\text { MON; }\end{array}$ \\
\hline $\begin{array}{l}\text { GRAU DE OXIDA- } \\
\text { ÇÃO-REDUÇÃO }\end{array}$ & $\begin{array}{l}\text { Influencia na microbiota residente } \\
\text { pela diferença de concentração de } \\
\text { oxigênio e ação dos radicais livres. }\end{array}$ & $\begin{array}{l}\text { Maior presença de anaeróbios restritos } \\
\text { (espécies disbiontes). }\end{array}$ & $\begin{array}{l}\text { (BARROSO; COR- } \\
\text { TELA; MOTA, 2014; } \\
\text { KIM et al., 2018). }\end{array}$ \\
\hline $\begin{array}{l}\text { NUTRIENTES } \\
\text { Podem ser endógenos (saliva e FSG) } \\
\text { ou exógenos (dieta). }\end{array}$ & $\begin{array}{l}\text { Síntese de ácidos e outros subprodutos } \\
\text { que modificam o pH local e lesam a mu- } \\
\text { cosa bucal. }\end{array}$ & $\begin{array}{l}\text { (NASRY et al., } \\
\text { 2016). }\end{array}$ \\
\hline $\begin{array}{l}\text { DEFESA DO ORGA- } \\
\text { NISMO }\end{array}$ & Efeito bactericida e bacteriostático. & $\begin{array}{l}\text { Maior presença de quadro de doenças in- } \\
\text { fecciosas. }\end{array}$ & (DARVEAU, 2010). \\
\hline
\end{tabular}

Fonte: Elaborada pelos autores. 
al., 2016). Diversos estudos demonstraram que as bactérias e seus subprodutos desempenham um papel fundamental na indução e, principalmente, na perpetuação das alterações patológicas que acometem a polpa e os tecidos periapicais (GEORGE et al., 2016; NASRY et al., 2016; ZANDONÁ; SOUZA, 2017). Ou seja, as interações bacterianas nas infecções endodônticas afetam sinergicamente ou antagonistamente na progressão da condição patológica e ressaltam a complexidade dos determinantes, que influenciam na patogenicidade da comunidade bacteriana composta (GEORGE et al., 2016).

Quanto ao aspecto das patologias pulpares, elenca-se como uma das características mais proeminentes dos microrganismos que afetam esse tecido, representado pelo gênero Enterococcus, a capacidade de colonização de superfícies inertes e biológicas (BARROSO; CORTELA; MOTA, 2014; ZANDONÁ; SOUZA, 2017). Nesse gênero, a espécie $E$. faecalis destaca-se por possuir proteção contra agentes antimicrobianos e fagócitos, mediando a adesão e invasão de células do hospedeiro, de forma a impedir a liberação de enzimas hidrolíticas por células polimorfonucleadas (PMNs), o que pode explicitar o seu domínio em infecções pulpares recorrentes e a sua característica de serem assintomáticas (NASRY et al., 2016; IKE, 2017).

Os métodos preventivos tradicionais para infecção oral visam ao controle mecânico (ou inespecífico) da placa. A antibioticoterapia sistêmica de curta duração, o uso tópico de antimicrobianos orais ou uso de colutórios específicos foram empregados como terapias coadjuvantes para o método mecânico do tratamento periodontal (KIM et al., 2018). Seu uso, entretanto, deve ser restrito porque a disseminação de espécies resistentes a essa classe de fármaco é um sério problema de saúde pública.

Outra ferramenta que pode ser usada para modular a microbiota são os probióticos, os quais são definidos como microrganismos vivos que conferem benefícios à saúde do hospedeiro, quando administrados em quantidades suficientes (BARROSO; CORTELA; MOTA, 2014; TERAl et al., 2015). Lactobacillus e Bifidobacterium são probióticos típicos que podem proporcionar muitos benefícios à saúde. Esses gêneros têm como principais características serem anti-infecciosos, anticarcinogênicos, anti-inflamatórios e possuem a capacidade de modulação imunológica com base na ação de seus metabólitos e componentes celulares (TERAl et al., 2015; IKE, 2017).

\section{Cárie Dentária}

A cárie dentária é uma das doenças crônicas mais comuns e com uma enorme carga na saúde global. A Organização Mundial da Saúde (OMS) estima a prevalência global de cárie entre $60 \%$ e $90 \%$ em crianças e quase universal em adultos (NASRY et al., 2016). Esta é uma patologia infecciosa polimicrobiana caracterizada pela desmineralização dos tecidos dentais e disbiose da microbiota, devido a alterações em seus fatores moduladores (HOLGERSON et al., 2015).

Sabe-se que dentes gravemente cariados podem ter um impacto importante na saúde geral, como na nutrição, crescimento e peso corporal especialmente em crianças, causando desconforto, dor e problemas no sono (TERAl et al., 2015; KIM et al., 2018).

No estudo de Kim et al. (2018) a microbiota oral foi analisada pelo sequenciamento do gene rRNA 16S. Dessa forma, notou-se que este micro-habitat foi mais diversificado em indivíduos livres de cárie do que naqueles com cárie dentária (grupo DC). Embora ambos os grupos tenham exibido mudanças na composição da microbiota, uma associação com a cárie foi encontrada pela predileção da função. A análise das funções microbianas potenciais revelou que Granulicatella, Streptococcus, Bulleidia, e Staphylococcus no grupo DC podem estar associados à invasão bacteriana de células do epitélio, sistema de fosfotransferase e metabolismo de D-alanina. Enquanto Neisseria, Lautropia e Leptotrichia, em indivíduos livres de cárie, estão associados a genes de proteínas de motilidade bacteriana, metabolismo do ácido linoleico e biossíntese de flavonoides, sugerindo que as diferenças na microbiota podem estar associadas à evolução da cárie. Esses resultados expandem a compreensão atual do significado funcional deste micro-habitat na doença cárie.

Apesar desses achados, ainda não está totalmente esclarecido o significado funcional da microbiota no desenvolvimento desta doença e sua progressão. Dessa forma, a identificação da associação entre a abordagem odontológica e essa microbiota é necessária para que se possa compreender completamente o seu papel na saúde bucal (NASRY et al., 2016; SHAN-JIANG et al., 2016; KIM et al., 2018).

\section{Doença Periodontal}

Um dos fatores etiológicos mais importantes da doença periodontal é a presença dos periodontopatógenos. O desenvolvimento clínico e a expressão da doença dependem dos fatores modificá- 
veis e não modificáveis de um hospedeiro suscetível (OCZKO et al., 2014). Em condições de saúde, o sulco gengival é colonizado principalmente por microrganismos Gram-positivos, que incluem Streptococcus spp. e espécies de Actinomyces, mas com a alteração na microbiota ocorre a colonização por bactérias Gram-negativas (NASRY et al., 2016).

A progressão da doença periodontal é favorecida pelas características morfológicas dos tecidos afetados, o que a distingue de outras doenças infecciosas (ALMEIDA et al., 2006). A resposta imune de cada indivíduo tem um papel importante no início e progressão desta doença e pode ser influenciada por fatores de risco (fumo, obesidade, diabetes e histórico familiar), biológicos e comportamentais (MEDINA; VEGA; ZULUAGA 2014; MORENO et al., 2017).

Devido ao estímulo perdurado do sistema imunológico diante da sua ineficiência contra os microrganismos imersos no biofilme, há alteração das condições normais da microbiota oral ao modificar os parâmetros que a regulam. Com isso, as mucosas que antes eram colonizadas por microrganismos simbiontes serão substituídas por espécies patogênicas, desencadeando processos patológicos (DARVEAU, 2010; MORENO et al., 2017).

Segundo Morais et al. (2006), as bactérias envolvidas com esta doença são representadas por três espécies em especial: Actinobacillus actinomycetemcomitans, espécie com capacidade de invadir células epiteliais bucais e células endoteliais vasculares humanas, além de induzirem a célula a iniciar o processo de apoptose; Porphyromonas gingivalis, espécie capaz de invadir células epiteliais e células endoteliais humanas e colaborar com o fenômeno de agregação plaquetária; Tannerella forsythensis, espécie com a propriedade de invadir células epiteliais e induzir a morte celular por apoptose.

\section{Correlações com patologias sistêmicas}

Estudos vêm demonstrando a relação das doenças bucais e sistêmicas (cardiopatias e infecções respiratórias, principalmente), ressaltando-se que inúmeras pesquisas se desenvolveram com resultados que evidenciam cada vez mais esta possível relação, entretanto os estudos ainda não são conclusivos (MORAIS et al., 2006; GADELHA; ARAÚJO, 2011; NASRY et al., 2016). Como as bactérias orais sempre invadem os vasos sanguíneos por meio da mucosa bucal, elas são causas potenciais de bacteremia e outras infecções sistêmicas (TERAl et al., 2015).
Muitos estudos indicam que a doença periodontal é uma possível fonte de liberação sistêmica de patógenos bacterianos e componentes pró-inflamatórios (sintetizados pelos periodontopatógenos). Dessa forma, esta patologia bucal é considerada um indicador de risco, que deve ser levada em conta durante a profilaxia e manejo da saúde geral (OCZKO et al., 2014).

A microbiota periodontal possui capacidade de gerar bacteremias e migrar para outros tecidos, nos quais iniciam o processo de necrose tecidual (MORENO et al., 2017). Os estudos microbiológicos realizados permitem detectar os mesmos microrganismos em amostras tanto subgengivais quanto cardiovasculares (GADELHA; ARAÚJO, 2011; MORAIS et al., 2006; MORENO et al., 2017).

O início e a progressão das periodontopatias envolvem um conjunto de eventos imunopatológicos e inflamatórios, com a participação de fatores modificadores locais, sistêmicos, ambientais e genéticos (OCZKO et al., 2014; MEDINA; VEGA, ZULUAGA, 2014). As doenças periodontais e as sistêmicas apresentam relações diretas e bidirecionais, gerando necessidade de envolvimento de múltiplas especialidades da área de saúde para devolver o equilíbrio do binômio saúde-doença (MORAIS et al., 2006; GADELHA; ARAÚJO, 2011).

Problemas bucais que alteram a modulação da microbiota oral atuam como foco de disseminação de microrganismos patogênicos com efeito metastático sistêmico, especialmente em pessoas com a saúde comprometida (MORAIS et al., 2006). Apesar de a literatura sugerir uma relação entre os microrganismos presentes na cavidade bucal e as patologias sistêmicas estes estudos não são satisfatórios para afirmar a existência de uma relação de causa/efeito entre as duas (CRUZ; NADANOVSKY, 2003; ALMEIDA et al., 2006; COSTALONGA; HERZBERG, 2014; NASRY et al., 2016).

Dessa forma, há necessidade da investigação da relação entre a microbiota oral e patologias sistêmicas por meio da utilização de estudos longitudinais mais rigorosos metodologicamente e envolvendo tamanhos populacionais maiores, para que se possa inferir uma relação de causa/efeito mais sólida. Para as pesquisas futuras destaca-se a importância da investigação da correlação da composição da microbiota residente da cavidade bucal com o desenvolvimento e progressão de neoplasias, além de buscar compreender as relações entre diferentes espécies de fungos e os outros membros da microbiota oral e, assim, possibilitar uma melhor compreensão sobre a patogenici- 
dade desses organismos. Esses novos conhecimentos permitirão novas abordagens terapêuticas para a prevenção e tratamento de complicações orais.

\section{Cardiopatias}

O principal fator responsável pela maioria dos casos de doenças cardiovasculares é a aterosclerose (GADELHA; ARAÚJO, 2011). Trata-se de uma doença vascular progressiva caracterizada por um espessamento da túnica íntima de artérias musculares. A teoria de que a aterosclerose passa por um processo inflamatório acentuou o interesse no papel de que alguns agentes infecciosos possam desempenhar no início ou mesmo na modelação da aterogênese (MORAIS et al., 2006; MORENO et al., 2017). Nesta perspectiva, inseriu-se na literatura a hipótese de as doenças periodontais terem um papel na formação de ateromas (ALMEIDA et al., 2006).

Efetivamente, vários agentes patógenos periodontais foram detectados em placas de ateroma, como é o caso da Porphyromonas gengivalis e o Actinobacillus actinomycetemcomitans (ALMEIDA et al., 2006; DARVEAU, 2010). Outra correlação encontrada é a bactéria anaeróbia, facultativa e Gram-negativa Aggregatibacter actinomycetemcomitans. Esta espécie é o membro mais prevalente do Grupo Hacek, no qual é fortemente relacionada à periodontite agressiva e endocardite (OCZKO et al., 2014; KAWAMOTO et al., 2016).

Para além da deteç̧ão de material genético de patógenos periodontais, a doença periodontal tem sido associada ao aumento dos níveis de marcadores pró-inflamatórios, os quais são reconhecidos indicadores de risco para as doenças cardiovasculares, como a proteína $C$ reativa, o fibrinogênio e contagem de leucócitos (ALMEIDA et al., 2006; MORAIS et al., 2017).

A literatura elenca entre as cardiopatias que são potencialmente desencadeadas por microrganismos orais a endocardite infecciosa, classificada como uma doença bacteriana infecciosa (CAMELO-CASTILLO et al., 2015; KAWAMOTO et al., 2016). Esta condição patológica é conceituada como uma inflamação do tecido interno das válvulas cardíacas, cuja ligação de bactérias à superfície de uma válvula desencadeia o crescimento de microcolônias de bactérias, células imunes, fibrina e plaquetas sanguíneas (ALMEIDA et al., 2006; SHAN-JIANG et al., 2016; MORENO et al., 2017). Relata-se que várias espécies de Streptococcus orais, como S. sanguinis, S. salivarius e S. oralis são isolados frequentemente de pacientes com endocardite (TERAl et al., 2015).
As evidências disponíveis ainda são escassas e suas interpretações são limitadas por potenciais vieses e situação de confusão. Os estudos não fornecem evidência epidemiológica convincente para uma associação causal entre doenças periodontais e doenças cardiovasculares, entretanto a possibilidade de as doenças bucais causarem doenças cardiovasculares ainda não pode ser descartada (ALMEIDA et al., 2006; DARVEAU, 2010; MORENO et al., 2017).

\section{Infecções Respiratórias}

Estudos indicam que as periodontopatias também influenciam no curso das infecções respiratórias, destacando-se as pneumonias (GADELHA; ARAÚJO, 2011). A pneumonia é uma infecção debilitante, em especial no paciente idoso e imunocomprometido (MORAIS et al., 2006). Nos hospitais, a pneumonia nosocomial exige atenção especial, uma vez que essa enfermidade está presente principalmente em pacientes com alteração de consciência ou que necessitam de ventilação mecânica (MORENO et al., 2017).

A higiene bucal deficiente é comum em pacientes internados em UTI, o que propicia a colonização do biofilme bucal por microrganismos patogênicos, especialmente por patógenos respiratórios, alterando a microbiota oral para uma relação que penderá para a origem de doenças bucais e, provavelmente, na sequência, sistêmicas (GEORGE et al., 2016; MORAIS et al., 2006). Com isso, nota-se que a quantidade de biofilme nesses pacientes aumenta com o tempo de internação, paralelamente há o aumento dos patógenos no biofilme bucal, o que contribui para um prognóstico desfavorável do caso (MORAIS et al., 2006; GADELHA; ARAÚJO, 2011).

De acordo com Almeida et al. (2006), a condição necessária para instalação e progressão da pneumonia bacteriana é a invasão por potenciais patógenos respiratórios, estes oriundos da cavidade oral e orofaringe. $O$ estabelecimento desta patologia ocorre pela aspiração para o trato respiratório inferior de secreções contidas nessas cavidades com a presença de cepas de bactérias Gram-negativas ou, menos frequentemente, por disseminação hematogênica originada de um foco a distância oriunda de uma bacteremia primária (ALMEIDA et al., 2006; MORAIS et al., 2006).

Entre os patógenos orais relacionados à pneumonia destacam-se Acinetobacter spp., Staphylococcus aureus, Klebsiella spp. e Enterobacter spp. (MORAIS et al., 2006; GADELHA; ARAÚJO, 2011). Almeida et al. (2006) observaram um aumento do risco de pneumo- 
nia por aspiração quando a bactéria Porphyromonas gingivalis, associada à doença periodontal, estava presente na placa bacteriana e saliva dos pacientes.

Apesar de a literatura sugerir uma associação entre os patógenos presentes na microbiota oral e as infecções respiratórias, esta correlação ainda não pode ser confirmada (ALMEIDA et al., 2006; GADELHA; ARAÚJO, 2011; MORENO et al., 2017).

\section{CONCLUSÃO}

Diante disso, a microbiota oral tem influência no binômio saúde-doença, especialmente sobre a saúde bucal ao atuar tanto na manutenção do equilíbrio quanto na origem de diversas doenças bucais. São necessários, no entanto, estudos mais abrangentes para esclarecer os mecanismos relacionados a essa associação.

Além disso, nota-se também que apesar de os estudos indicarem a associação entre a microbiota oral e patologias sistêmicas (principalmente as cardiopatias e infeções respiratórias), ainda não há a certeza dessa conexão. Assim, o melhor é o contínuo incentivo à prevenção ao focar no cuidado com a saúde bucal. Salienta-se, ainda, a necessidade de estudos mais aprofundados para esclarecer e determinar qual a real associação entre a microbiota oral e as patologias destacadas.

\section{REFERÊNCIAS}

ALMEIDA, R. F. et al. Associação entre doença periodontal e patologias sistêmicas. Rev. Port. Clin. Geral, v. 22, n. 1, p. 379-390, 2006.

BARROSO, M. G.; CORTELA, D. C. B.; MOTA, W. P. Endocardite bacteriana: da boca ao coração. Rev. Ciência e Estudos Acadêmicos de Medicina, v. 1, n. 2, p. 47-57, 2014.

CAMELO-CASTILLO, A. J. et al. Subgingival microbiota in health compared to periodontitis and the influence of smoking. Frontiers in Microbiology, v. 6, n. 119, p. 1-12, 2015.

COSTALONGA, M.; HERZBERG, M. C. The oral microbiome and the immunobiology of periodontal disease and caries. Immunol Lett, v. 162, n. 200, p. 22-38, 2014.

CRUZ, J. C.; NADANOVSKY, P. Doenças periodontais causam doenças cardiovasculares? Análise das evidências epidemiológicas. Cad. Saúde Pública, v. 19, n. 2, p. 357-368, 2003.

DARVEAU, R. P. Periodontitis: a polymicrobial disruption of host homeostasis. Nature Reviews Microbiology, v. 8, n. 1, p. 481-490, 2010.

GADELHA, R. L; ARAÚJO, J. M. S. Relação entre a presença de microrganismos patogênicos respiratórios no biofilme dental e pneumonia nosocomial em pacientes em Unidade de Terapia Intensiva: revisão de literatura. Revista Saúde e Ciência, v. 2, n. 1, p. 95-104, 2011.

GALVÃO, T. F.; PANSANI, T. S. A. Principais itens para relatar revisões sistemáticas e meta-análises: a recomendação Prisma. Epidemiol. Serv. Saúde, v. 24, n. 2, p. 335-342, 2015.
GEORGE, N. et al. Oral microbiota species in acute apical endodontic abscesses. Journal of Oral Microbiology, v. 8, n. 1, p. 1-9, 2016.

GHANNOUM, M. A. et al. Characterization of the Oral Fungal Microbiome (Mycobiome) in Healthy Individuals. PLOS Pathogens, v. 6, n. 1, p. 1-8, 2010.

HOLGERSON, P. L. et al. Maturation of Oral Microbiota in Children with or without Dental Caries. PLOS ONE, v. 1, n. 1, p. 1-20, 2015.

HOMD. HUMAN ORAL MICROBIOME DATABASE. 2018. Página inicial. Disponível em: http://www.homd.org/. Acesso em: 6 dez. 2018.

HONGSEN, Z. et al. Variations in oral microbiota associated with oral câncer. Scientific Reports, v. 7, n. 1, p. 1-10, 2017.

IKE, Y. Pathogenicity of Enterococci. Nihon Sajkingaku ZasShi, v. 2, n. 72, p. 189-211, 2017.

KAWAMOTO, D. et al. Alteration of Homeostasis in Pre-osteoclasts Induced by Aggregatibacter actinomycetemcomitans CDT. Fronteirs in Cellular and Infection Microbiology, v. 6, n. 33, p. 1-10, 2016.

KIM, B. et al. Association of Salivary Microbiota With Dental Caries Incidence With Dentine Involvement after 4 years. J. Microbiol. Biotechnol, v. 28, n. 3, p. 454-464, 2018.

MEDINA, C. M. A.; VEGA, J. A.; ZULUAGA I. C. G. Correlación de bacilos entéricos Gram-negativos con parámetros clínicos y demográficos de pacientes con periodontitis crónica. Av Periodon Implantol, v. 26, n. 2, p. 77-82, 2014.

MOON, J; LEE, J. Probing the diversity of healthy oral microbiome with bioinformatics approaches. BMB Reports, v. 49, n. 12, p. 662-570, 2016.

MORAIS, T. M. N. et al. A importância da atuação odontológica em pacientes internados em Unidade de Terapia Intensiva. RBTI, v. 18, n. 4, p. 412-417, 2006.

MORENO, S. et al. Microbiota periodontal y microorganismos aislados de válvulas cardíacas en pacientes sometidos a cirurgía de reemplazo de válvulas en una clínica de Cali, Colombia. Biomédica, v. 37, n. 1, p. 516-525, 2017.

NASRY, B. et al. Diversity of the Oral Microbiome and Dental Health and Disease. Int J Clin Med Microbiol, v. 1, n. 1, p. 1-8, 2016.

OCZKO, M. R. et al. Porphyromonas gingivalis in periodontal pockets and heart valves. Virulence, v. 5, n. 4, p. 575-580, 2014. POZHITKOV, A. E. et al. Towards microbiome transplant as a therapy for periodontitis: na exploratory study of periodontitis microbial signature contrasted by oral health, caries and edentulism. BMC Oral Health, v. 15, n. 1, p. 125-135, 2015.

SHAN-JIANG, X. G. et al. Salivary Microbiome Diversity in Caries-Free and Caries-Affected Children. International Journal of Molecular Sciences, v. 17, n. 1.978, p. 1-13, 2016.

TERAI, T. et al. Screening of Probiotic Candidates in Human Oral Bacteria for the Prevention of Dental Disease. PLOS ONE, v. 10, n. 6, p. 1-20, 2015.

ZANDONÁ, J.; SOUZA, M. A. Características microbiológicas, patogenicidade e viabilidade do Enterococcus faecalis e seu cultivo in vitro em pesquisas microbiológicas na área da Endodontia. RFO, v. 22, n. 2, p. 255-260, 2017. 